\title{
Genetic analysis of predicted fatty acid profiles of milk from Danish Holstein and Danish Jersey cattle populations
}

\author{
L. Hein, ${ }^{*}$ L. P. Sørensen, ${ }^{*}$ M. Kargo, ${ }^{*} \dagger$ and A. J. Buitenhuis $\dagger^{1}$ \\ *SEGES, Agro Food Park 15, 8200 Aarhus N, Denmark \\ †Aarhus University, Center for Quantitative Genetics and Genomics, Department of Molecular Biology and Genetics, Blichers Allé 20, \\ PO Box 50, DK-8830 Tjele, Denmark
}

\section{ABSTRACT}

The objective of this study was to assess the genetic variability of the detailed fatty acid (FA) profiles of Danish Holstein (DH) and Danish Jersey (DJ) cattle populations. We estimated genetic parameters for 11 FA or groups of FA in milk samples from the Danish milk control system between May 2015 and October 2016. Concentrations of different FA and FA groups in milk samples were measured by mid-infrared spectroscopy. Data used for parameter estimation were from 132,732 first-parity DH cows and 21,966 first-parity DJ cows. We found the highest heritabilities for test day measurements in both populations for short-chain FA $(\mathrm{DH}=0.16$; DJ $=0.16)$ and $\mathrm{C} 16: 0(\mathrm{DH}=0.14$; DJ $=$ $0.16)$. In $\mathrm{DH}$, the highest heritabilities were also found for saturated FA and monounsaturated FA (both populations: 0.15). Genetic correlations between the fatty acid traits showed large differences between DH and DJ for especially short-chain FA with the other FA traits measured. Furthermore, genetic correlations of total fat with monounsaturated FA, polyunsaturated FA, shortchain FA, and C16:0 differed markedly between DH and DJ populations. In conclusion, we found genetic variation in the mid-infrared spectroscopy-predicted FA and FA groups of the DH and DJ cattle populations. This finding opens the possibility of using genetic selection to change the FA profiles of dairy cattle.

Key words: fatty acid profile, genetic parameter, dairy cow, population

\section{INTRODUCTION}

Milk contains important nutrients for young animals and humans. A major component in milk, fat consists almost entirely $(\sim 98 \%)$ of triglycerides, which are composed of a glycerol backbone and 3 fatty acids (FA). More than 400 individual FA have been discovered in milk (Jensen et al., 1991), which are typically divided

Received May 24, 2017.

Accepted October 30, 2017

${ }^{1}$ Corresponding author: bart.buitenhuis@mbg.au.dk into SFA (65-70\% of total fat), MUFA (27-33\%), and PUFA (3-5\%). From a human nutritional standpoint, it would be beneficial to increase the unsaturated fat content of milk. Ingestion of unsaturated fats has a generally positive effect on serum cholesterol levels; however, a direct negative effect of SFA is debatable (Lawrence, 2013; Bier, 2016; Parodi, 2016). Furthermore, C16:0 has been associated with negative effects on cardiovascular disease in humans (Mensink et al., 2003; Givens, 2010).

In Denmark, interest has increased regarding the development of new dairy products with fat as an important component. The formation of FA in milk is influenced by many factors, including lactation stage (Craninx et al., 2008; Stoop et al., 2008), season (Heck et al., 2009), management or feeding regimen (Moate et al., 2007; Coppa et al., 2013), and genetics (Soyeurt et al., 2006b; Stoop et al., 2008; Krag et al., 2013). For changing the FA profile in milk by genetic selection, it is important to clarify the genetics underlying milk FA in different dairy cattle breeds. This clarification requires large amounts of phenotypic data (i.e., FA measurements). However, measuring the FA concentration in milk has been a challenge, because the gold standard for measuring FA is GC. Owing to its time-consuming and costly nature, GC is not well suited for large-scale screening. Alternatively, mid-infrared spectrometry (MIRS) can be used for the high-throughput analysis of milk samples (Soyeurt et al., 2006a; De Marchi et al., 2014).

In the current study, we investigated the possibility of differentiating the milk FA profile by genetics. For that purpose, the Danish dairy cattle population was routinely screened for different FA groups by using MIRS. We present the results of the genetic and phenotypic analyses of FA data from the Danish Holstein (DH) and Danish Jersey (DJ) cattle populations.

\section{MATERIALS AND METHODS}

\section{Data and Animals}

Milk samples were collected during regular herd testing from May 2015 to October 2016 from primiparous 
Table 1. Total number of fatty acid observations (8-305 DIM) and number of cows per breed and production system after editing, based on data from May 2015 to October 2016

\begin{tabular}{|c|c|c|c|c|c|c|}
\hline \multirow[b]{3}{*}{ Breed } & \multicolumn{4}{|c|}{ Production system } & & \\
\hline & \multicolumn{2}{|c|}{ Conventional } & \multicolumn{2}{|c|}{ Organic } & \multicolumn{2}{|r|}{ Total } \\
\hline & Cows & Observations & Cows & Observations & Cows & Observations \\
\hline Danish Holstein & 121,337 & 558,198 & 11,394 & 54,123 & 132,731 & 612,321 \\
\hline Danish Jersey & 20,155 & 88,023 & 1,812 & 7,897 & 21,967 & 95,920 \\
\hline Total & 141,492 & 646,221 & 13,206 & 62,020 & 154,698 & 708,241 \\
\hline
\end{tabular}

DH and DJ cows participating in the Danish herd testing scheme. Samples were analyzed at a certified laboratory (Eurofins, Vejen, Denmark) with a MilkoScan FT+/FT6000 (Foss, Hillerød, Denmark) equipped with special software (Foss Application Note 64, Foss) for predicting 7 FA fractions, namely SFA, MUFA, PUFA, short-chain FA (SCFA), medium-chain FA (MCFA), long-chain FA (LCFA), and trans FA (TFA), as well as 4 individual FA, namely C14:0, C16:0, C18:0, and C18:1. Raw FA measurements, provided as grams of FA per $100 \mathrm{~g}$ of milk, were stored in the Danish Cattle Database (SEGES, Skejby, Denmark). In addition to FA measurements, information about milk yield, total fat content, calving date, parity, breed, and production system was extracted from the Danish Cattle Database (SEGES).

We applied numerous consecutive editing procedures to ensure that we obtained high-quality FA observations. Observations were checked for the following conditions and removed if any condition was met. (1) One or more of the $11 \mathrm{FA}$ fractions was missing from an observation. (2) The PUFA concentration was greater than or equal to the MUFA concentration. (3) The ratio of the sum of the SFA, MUFA, and PUFA contents to the total fat content was less than 0.825 or greater than 1.075 (values chosen such that $5 \%$ of remaining observations were removed). (4) The ratio of the sum of the SCFA, MCFA, and LCFA contents to the sum of the SFA, MUFA, and PUFA contents was less than 0.84 or greater than 1.04 (values chosen such that $1 \%$ of remaining observations were removed). Finally, (5) each FA fraction was checked for outliers. The size of extreme values was chosen such that $1 \%$ of remaining observations were removed. If more than 1 observation per cow per herd test day was observed, then the mean value of the observations was used. Moreover, an observation was removed if the daily milk yield was less than $2 \mathrm{~kg}$ or the total fat percentage was greater than 8 or $12 \%$ for $\mathrm{DH}$ and $\mathrm{DJ}$, respectively, as these conditions could indicate the presence of a metabolic disease (e.g., ketosis). The lactation period was defined as 8 to 305 DIM. This interval was chosen to avoid any interference caused by colostrum production in the beginning of lactation, and because 305 DIM defines the endpoint of lactation when performing genetic evaluation of dairy cattle in Nordic countries.

Three additional editing steps were performed. (1) Daughters of a sire with fewer than 10 daughters were removed from the data set. (2) Cows that changed herd during the sampling period were removed from the data set. (3) The last step was reduction of the number of animals to enable both phenotypic and genetic analyses of especially the large DH data. This was done by randomly removing all records from every second cow from the data set. Means and variances of the FA variables were checked to ensure that data were unbiased after reduction. The sizes of the final data sets are shown in Table 1.

\section{Definition of Traits}

For each FA fraction, 2 trait groups were defined: (1) total test day FA production in grams and (2) percentage of test-day FA, defined as the ratio of the content of the FA fraction to the sum of the SFA, PUFA, and MUFA contents. Total fat in grams was determined across the lactation (8-305 DIM). Genetic parameters were estimated based on test day measurements across the lactation period. The average number of observations per cow across the lactation period was 4.6 (SD $=2.7)$ for $\mathrm{DH}$ and $4.4(\mathrm{SD}=2.5)$ for DJ. Minimum number of observations per cow was 1 for both breeds.

\section{Data Analysis}

Descriptive statistical analysis was performed by using the HPMIXED procedure in SAS (version 9.3, SAS Institute Inc., Cary, NC) to study the effects of breed (2 levels; DH and DJ), production system (2 levels; organic and conventional), month $\times$ year (18 levels), 30-d lactation interval (10 levels), and production system $\times$ (month $\times$ year). The following linear mixed model was used:

$$
\mathbf{y}=\mathbf{X b}+\mathbf{Q h}+\mathbf{Z a}+\mathbf{e}
$$


where $\mathbf{y}$ is a vector of test-day observations, $\mathbf{b}$ is a vector of fixed effects as described above, $\mathbf{h}$ is a vector of random herd effects nested within production system, a is a vector of random animal effects nested within herd and breed, $\mathbf{e}$ is the vector of residual effects, and $\mathbf{X}, \mathbf{Q}$, and $\mathbf{Z}$ are incidence matrices relating records to fixed, herd, and animal effects, respectively. A significance level of $\alpha=0.05$ was used to determine significant differences between least squares means (LSM) using a $t$-test. All estimates are shown LSM.

\section{Estimation of Genetic Parameters}

Estimation of variance components for estimation of heritability and repeatability were estimated within breed for each FA fraction and total fat using the following univariate repeatability linear animal model:

$$
\mathbf{y}=\mathbf{X b}+\mathbf{Q h}+\mathbf{Z a}+\mathbf{W p e}+\mathbf{e},
$$

where $\mathbf{y}$ is the vector of test-day observations, $\mathbf{b}$ is the vector of fixed effects, $\mathbf{h}$ is the vector of random herd effects, $\mathbf{a}$ is the vector of random animal effects, pe is the vector of permanent environmental effects, e is the vector of residual effects, and $\mathbf{X}, \mathbf{Q}, \mathbf{Z}$, and $\mathbf{W}$ are incidence matrices relating records to fixed, herd, animal, and permanent environmental effects, respectively. Fixed effects were the month $\times$ year of recording and a fixed regression accounting for the variability in early lactation, determined by fitting a lactation curve with the following function (Wilmink, 1987):

$$
y_{t}=a+b e^{-k t}+c t,
$$

where $y_{t}$ is FA content in grams or percent at $t$ DIM, and $a, b$, and $c$ are regression coefficients. The parameters jointly describe the curve shape: $a$ sets the amplitude of daily FA content, $b$ is the acceleration in early lactation, $c$ is the linear decline after the peak, and $k$ affects the duration of the acceleration period (fixed at $k=0.05)$ (Wilmink, 1987).

Genetic correlations between the FA percentage and total fat and genetic correlations among all predicted FA fractions and individual FA, both in percentage and grams, were estimated by using bivariate models with the same effects as model [1]. Relationships were traced back for 3 generations, resulting in a total of 474,801 and 138,237 animals in the pedigrees for DH and DJ, respectively.

The within-herd heritability was calculated as

$$
h^{2}=\frac{\sigma_{a}^{2}}{\sigma_{a}^{2}+\sigma_{p e}^{2}+\sigma_{e}^{2}},
$$

where $\sigma_{a}^{2}$ is the additive genetic variance, $\sigma_{p e}^{2}$ is the permanent environmental variance, and $\sigma_{e}^{2}$ is the residual variance. The genetic correlation $\left(r_{g}\right)$ was calculated as

$$
r_{g}=\frac{\operatorname{cov}_{a, t 1 t 2}}{\sigma_{a, t 1} \sigma_{a, t 2}}
$$

where $t 1$ and $t 2$ are trait 1 and trait 2 , respectively, and $\sigma_{a, t 1}$ and $\sigma_{a, t 2}$ are the additive genetic standard deviations of trait 1 and trait 2, respectively.

The (co)variance components were obtained by using the AI-REML algorithm included in the DMU package (Madsen and Jensen, 2007). Standard errors of heritabilities, repeatabilities, and genetic correlations were estimated by using Taylor series approximation.

\section{RESULTS}

It was necessary to reduce the amount of data to be able to perform both descriptive and genetic analysis with the chosen models. We collected data from 276,011 DH cows $(\sim 8.5 \%$ kept under organic conditions $)$ and 45,316 DJ cows ( $\sim 8 \%$ kept under organic conditions). These numbers were approximately halved to be able to run analyses with the chosen models. Data reduction was made to avoid creating biased data. This was achieved as shown by the examples of the means and standard deviation for SFA and C16:0 before and after data reduction (Table 2); neither SFA nor C16:0 was affected by the reduction step. Similar results were achieved for the remaining FA groups (data not shown).

\section{Factors Affecting FA Content}

Table 3 presents the LSM results of the 11 FA groups. In general, the DJ population had higher SFA content and lower MUFA and PUFA contents than the DH population. This result is consistent with the subtraits of higher SCFA, MCFA, C16:0, and C14:0 contents for DJ compared with DH. By contrast, the LCFA, TFA, C18:0, and C18:1 contents were higher in DH compared with DJ. Milk from organic cows had lower SFA content and higher PUFA content compared with milk from conventional cows (Table 3). The difference in MUFA content between the 2 production systems was not significant. Milk composition changed over the year, with reduced SFA and increased MUFA and PUFA contents in the summer for organic compared with conventional milk (Figure 1A-1B). The SCFA content was generally higher in the organic milk compared with the conventional milk (Figure 1C). We noted lower C16:0 content 
Table 2. Comparison of means (percent of total fat with SD in parentheses) of selected fatty acid content before and after data reduction in Danish Jersey (DJ) and Danish Holstein (DH)

\begin{tabular}{lccccc}
\hline & \multicolumn{2}{c}{ DH } & & \multicolumn{2}{c}{ DJ } \\
\cline { 2 - 3 } \cline { 5 - 6 } Trait & Before & After & & Before & After \\
\hline SFA & $67.99(4.15)$ & $67.98(4.15)$ & & $72.07(3.36)$ & $72.06(3.36)$ \\
C16:0 & $29.80(3.10)$ & $29.80(3.10)$ & & $31.78(2.68)$ & $31.77(2.69)$ \\
\hline
\end{tabular}

in the spring and summer months for the organic milk compared with the conventional milk (Figure 1D).

\section{Heritability}

Heritability estimates for test-day measurements of FA proportions as the percentage of total fat for the different FA groups and individual FA are presented in Table 4 and 5 for DH and DJ, respectively. In general, heritability estimates across lactation (8-305 DIM) were similar for DH and DJ. The highest heritability was estimated for SCFA in both DH and DJ (0.16), whereas the lowest heritability was estimated for TFA in both DH and DJ (0.07).

Table 6 shows estimates of repeatability. The highest repeatability was found for SCFA for both DH (0.35) and DJ (0.31), whereas the lowest repeatability was found for TFA (0.12 in both breeds). Standard errors of the repeatabilities were in the range of 0.002 to 0.01 , with the largest values being obtained for DJ. Supplemental Table S1 (https://doi.org/10.3168/jds.2017 -13225) reports the heritability and repeatability values for the same traits, expressed as total output (g). Ex-

Table 3. Breed and production system LSM for the 11 fatty acid fractions across lactation (8-305 DIM), given as the percentage of the sum of the SFA, MUFA, and PUFA content

\begin{tabular}{|c|c|c|c|c|}
\hline \multirow[b]{2}{*}{ Trait $^{1}$} & \multicolumn{2}{|c|}{ Breed $^{2}$} & \multicolumn{2}{|c|}{ Production system } \\
\hline & $\mathrm{DH}$ & DJ & Conventional & Organic \\
\hline SFA & $67.46^{\mathrm{a}}$ & $72.08^{\mathrm{b}}$ & $69.96^{\mathrm{c}}$ & $69.59^{\mathrm{d}}$ \\
\hline MUFA & $28.48^{\mathrm{a}}$ & $24.38^{\mathrm{b}}$ & $26.35^{\mathrm{a}}$ & $26.51^{\mathrm{a}}$ \\
\hline PUFA & $4.06^{\mathrm{a}}$ & $3.55^{\mathrm{b}}$ & $3.70^{\mathrm{a}}$ & $3.91^{\mathrm{b}}$ \\
\hline SCFA & $11.14^{\mathrm{a}}$ & $12.13^{\mathrm{b}}$ & $11.38^{\mathrm{c}}$ & $11.89^{\mathrm{d}}$ \\
\hline LCFA & $40.25^{\mathrm{a}}$ & $37.34^{\mathrm{b}}$ & $38.39^{\mathrm{c}}$ & $39.21^{\mathrm{d}}$ \\
\hline MCFA & $42.34^{\mathrm{a}}$ & $47.55^{\mathrm{b}}$ & $45.73^{\mathrm{c}}$ & $44.15^{\mathrm{d}}$ \\
\hline TFA & $3.67^{\mathrm{a}}$ & $2.98^{\mathrm{b}}$ & $3.16^{\mathrm{c}}$ & $3.49^{\mathrm{d}}$ \\
\hline C18:1 & $24.85^{\mathrm{a}}$ & $21.60^{\mathrm{b}}$ & $23.07^{\mathrm{c}}$ & $23.37^{\mathrm{d}}$ \\
\hline C16:0 & $29.25^{\mathrm{a}}$ & $31.45^{\mathrm{b}}$ & $30.74^{\mathrm{c}}$ & $29.96^{\mathrm{d}}$ \\
\hline C14:0 & $11.07^{\mathrm{a}}$ & $11.49^{\mathrm{b}}$ & $11.42^{\mathrm{c}}$ & $11.15^{\mathrm{d}}$ \\
\hline C18:0 & $11.23^{\mathrm{a}}$ & $11.15^{\mathrm{b}}$ & $11.12^{\mathrm{a}}$ & $11.25^{\mathrm{b}}$ \\
\hline
\end{tabular}

$\overline{{ }^{\mathrm{a} d} \text { Values with different superscripts are significantly different }(P<}$ $0.05)$.

${ }^{1}$ Trait: SCFA = small-chain fatty acid; LCFA = long-chain fatty acid; $\mathrm{MCFA}=$ medium-chain fatty acid; TFA $=$ trans fatty acid .

${ }^{2}$ Breed: DH $=$ Danish Holstein, DJ = Danish Jersey. cept for MUFA and TFA in both breeds and SCFA and C16:0 in DJ, the heritability and repeatability results of the different FA or groups of FA were higher when expressed as the total output than when expressed as the percentage of total fat.

\section{Correlations to Total Fat}

Table 7 presents the genetic and phenotypic correlations between the content of single FA, FA groups, and total fat for both cattle populations. Genetic correlations between the FA traits and total fat were generally stronger in DH than in DJ. Standard errors of the genetic correlations were in the range of 0.03 to 0.09 , with the largest values being observed for DJ. Signs of the correlations were the same in both populations. However, for C18:0, DH expressed a negative low correlation to total fat $(-0.14)$, whereas the genetic correlation for DJ was 0. The highest positive correlation was found for the SFA group in both DH and DJ, whereas PUFA and MUFA had strong negative correlations to total fat in both DH and DJ. Phenotypic correlations between the individual FA and FA groups to total fat were much lower than the genetic correlations in both DH and DJ.

\section{Correlations Between FA Groups}

The genetic and phenotypic correlations among the FA traits are presented in Tables 4 and 5 for $\mathrm{DH}$ and DJ, respectively. Several correlations could not be estimated because of part-whole relationships between the response variables. Genetic correlations between the FA traits showed large differences between $\mathrm{DH}$ and DJ; for example, SCFA and MUFA $(\mathrm{DH}=-0.69$; DJ $=-0.33)$, SCFA and PUFA $(\mathrm{DH}=0.05 ; \mathrm{DJ}=0.52)$, SCFA and MCFA $(\mathrm{DH}=0.30 ; \mathrm{DJ}=-0.27)$, SCFA and TFA $(\mathrm{DH}=-0.19 ; \mathrm{DJ}=0.16), \mathrm{SCFA}$ and C16:0 $(\mathrm{DH}$ $=0.04 ; \mathrm{DJ}=-0.29)$. Whereas the genetic correlations between SFA and MUFA (DH and DJ $=-0.99$ ), SFA and TFA (DH $=-0.49$ DJ $=-0.47)$, SFA and C18:1 $(\mathrm{DH}=-0.95 ; \mathrm{DJ}=-0.94), \mathrm{C} 18: 0$ and PUFA $(\mathrm{DH}=$ 0.06 ; DJ $=0.08), \mathrm{C} 18: 0$ and $\mathrm{C} 16: 0(\mathrm{DH}=-0.30$; DJ $=-0.28)$, and $\mathrm{C} 18: 0$ and $\mathrm{C} 14: 0(\mathrm{DH}$ and $\mathrm{DJ}=-0.67)$ did not differ between the DH and DJ breed. 


\section{DISCUSSION}

We estimated genetic parameters for specific FA and FA groups, which we determined by MIRS in DH and DJ cattle. Measurements were based on all cows that were participating in the Danish milk recording program. This approach resulted in very accurate genetic parameters (small SE) for the specific individual FA and FA groups despite the necessity of reducing data.
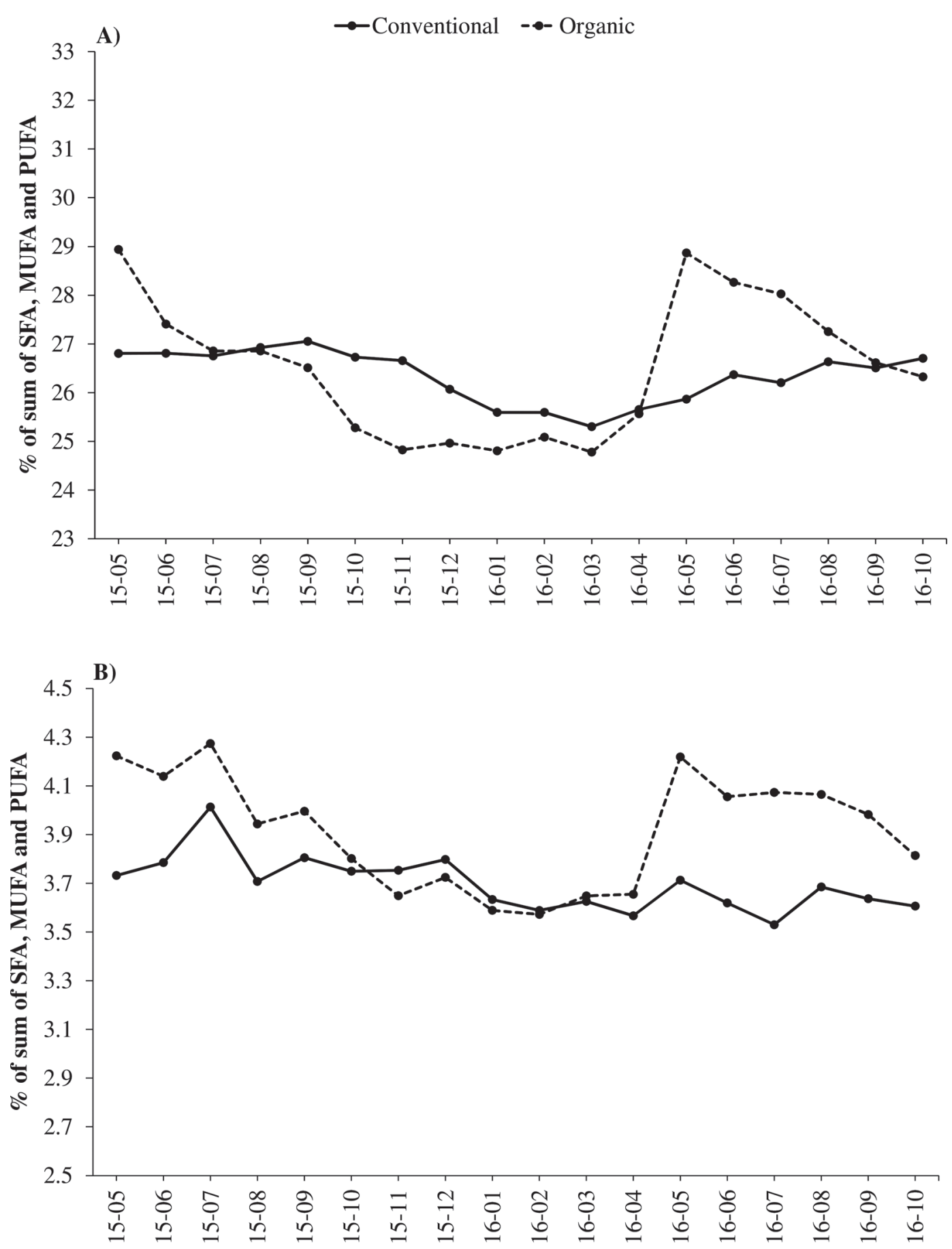

\section{Date (yy-mm)}

Figure 1. Average concentrations of MUFA (A), PUFA (B), short-chain fatty acids, (C) and C16:0 (D) relative to the sum of the concentrations of SFA, MUFA, and PUFA in milk obtained from cows raised in conventional and organic farms, respectively. 


\section{Choice of Methods}

We had access to large amounts of FA from all Danish DH and DJ herds participating in the Danish milk recording program. This meant that some compromises had to be made to facilitate the data analysis. Predictions of FA content were heavily edited to have data as clean as possible. The model choice and the large amount of data put limitations on computer capacity; thus, it was necessary to reduce the amount of data.
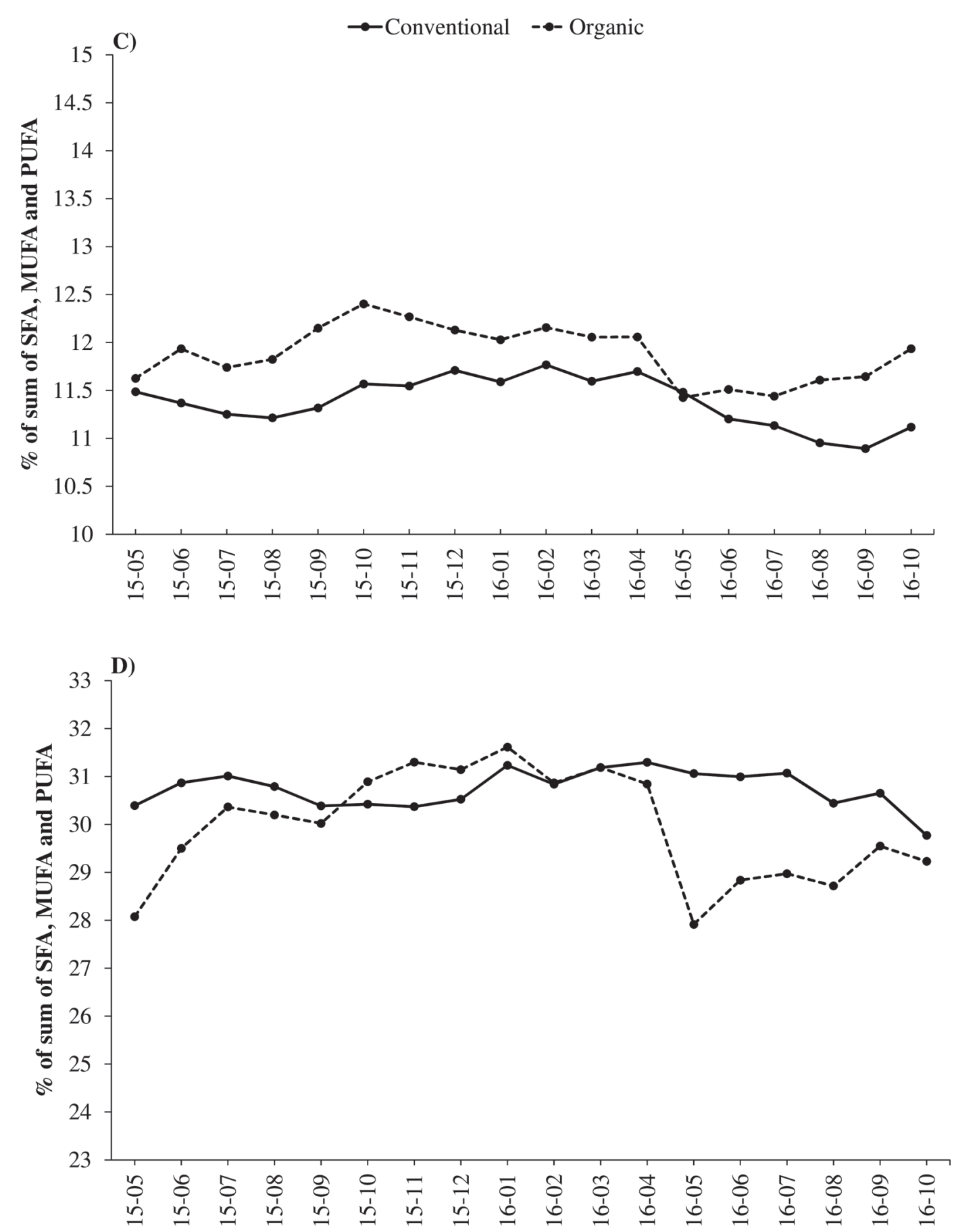

Date (yy-mm)

Figure 1 (Continued). Average concentrations of MUFA (A), PUFA (B), short-chain fatty acids, (C) and C16:0 (D) relative to the sum of the concentrations of SFA, MUFA, and PUFA in milk obtained from cows raised in conventional and organic farms, respectively. 
Table 4. Heritabilities ${ }^{1}$ on diagonal, genetic (below diagonal), and phenotypic (above diagonal) correlations between content (\% of total fat) of 4 individual fatty acids (FA) and 7 FA groups for Danish Holstein across lactation (8-305 DIM) ${ }^{2}$

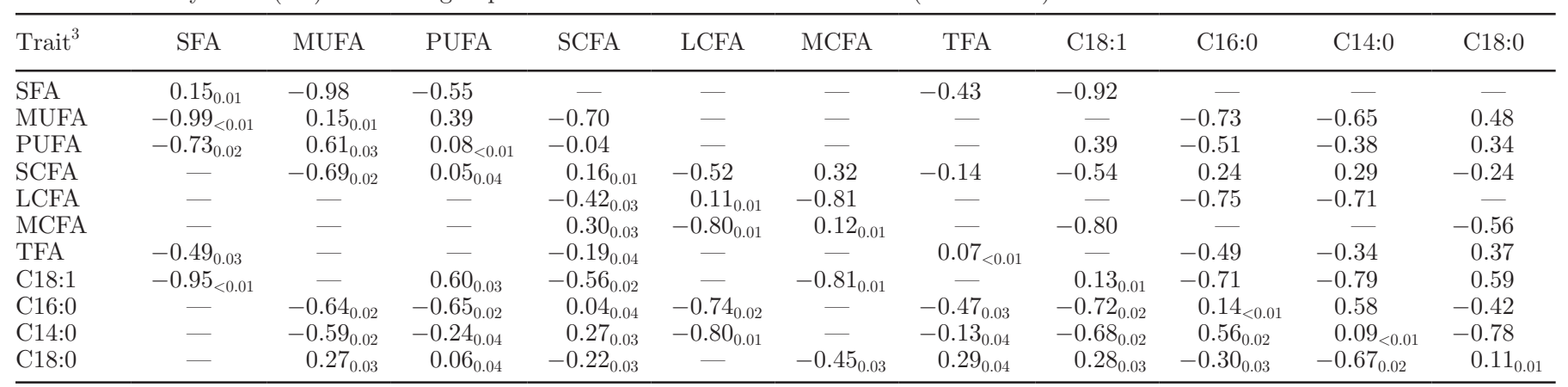

${ }^{1} \mathrm{SE}$ in subscript.

${ }^{2}-=$ correlation could not be estimated because of part-whole relationship between the response variables.

${ }^{3}$ Trait: SCFA = small-chain fatty acid; LCFA = long-chain fatty acid; MCFA = medium-chain fatty acid; TFA = trans fatty acid.

The DJ data were much less compared with DH data, so initially the DJ analyses could be run using the full data set. Analysis of the reduced data set confirmed that reduction of data did not affect estimation of either fixed effects or on the genetic parameters.

Narayana et al. (2017) showed that heritabilities of predicted FA groups change according to lactation stage. They applied a random regression model with a Gibbs sampling approach for estimation of variance components. In the initial analyses of the Danish FA data we estimated variance components within 30-d intervals across the lactation using FA means within intervals (Hein et al., 2016). We also found variation in heritabilities based on a sire model across the lactation; for example, SCFA content varied between 0.27 and 0.32 , which is higher, on average, but with less variation compared with Narayana et al. (2017). The next step was to apply a more complex animal model taking repeated measurements into account to make sure that it was possible to estimate variance components with the amount of data available. Applying a random regression model straight away was not possible given the constraint of the current project. A next step may be to apply a random regression model better suited for this type of data.

\section{Breed Differences}

Clear differences in milk composition between $\mathrm{DH}$ and DJ cattle were found. For example, DJ had higher SFA and lower UFA contents than DH cattle. These findings are consistent with previously reported differences between Holstein and Jersey breeds obtained after MIRS analysis (Soyeurt et al., 2006a; Maurice-van Eijndhoven et al., 2013). The GC measurements also showed that milk from DJ had higher SFA and lower UFA contents than did milk from DH cattle (Poulsen et al., 2012). Compared with Holstein cattle, Jersey cattle showed higher de novo synthesis of milk FA (Beaulieu and Palmquist, 1995). This greater synthesis may ex-

Table 5. Heritabilities ${ }^{1}$ on diagonal, genetic (below diagonal) and phenotypic (above diagonal) correlations between content (\% of total fat) of 4 individual fatty acids (FA) and 7 FA groups for Danish Jersey across lactation (8-305 DIM) ${ }^{2}$

\begin{tabular}{|c|c|c|c|c|c|c|c|c|c|c|c|}
\hline Trait $^{3}$ & SFA & MUFA & PUFA & SCFA & LCFA & MCFA & TFA & C18:1 & C16:0 & C14:0 & C18:0 \\
\hline SFA & $0.10_{0.01}$ & -0.99 & -0.60 & - & - & - & -0.47 & -0.92 & - & - & - \\
\hline MUFA & $-0.99_{<0.01}$ & $0.10_{0.01}$ & 0.45 & -0.57 & - & - & - & - & -0.75 & -0.71 & 0.54 \\
\hline PUFA & $-0.64_{0.05}$ & $0.50_{0.07}$ & $0.11_{0.01}$ & 0.06 & - & - & - & 0.46 & -0.59 & -0.45 & 0.35 \\
\hline SCFA & - & $-0.33_{0.08}$ & $0.52_{0.07}$ & $0.16_{0.01}$ & -0.47 & 0.18 & -0.06 & -0.40 & 0.13 & 0.23 & -0.23 \\
\hline LCFA & - & - & - & $-0.21_{0.08}$ & $0.09_{0.01}$ & -0.77 & - & - & -0.71 & -0.72 & - \\
\hline MCFA & - & - & - & $-0.27_{0.08}$ & $-0.68_{0.05}$ & $0.12_{0.01}$ & - & -0.81 & - & - & -0.54 \\
\hline TFA & $-0.47_{0.08}$ & - & - & $0.16_{0.09}$ & - & - & $0.07_{<0.01}$ & - & -0.50 & -0.45 & 0.44 \\
\hline C18:1 & $-0.94_{0.01}$ & - & $0.47_{0.07}$ & $-0.24_{0.08}$ & - & $-0.71_{0.04}$ & - & $0.10_{0.01}$ & -0.72 & -0.83 & 0.63 \\
\hline C16:0 & - & $-0.73_{0.04}$ & $-0.77_{0.04}$ & $-0.29_{0.08}$ & $-0.74_{0.04}$ & - & $-0.60_{0.06}$ & $-0.75_{0.04}$ & $0.16_{0.01}$ & 0.55 & -0.37 \\
\hline C14:0 & - & $-0.70_{0.05}$ & $-0.33_{0.08}$ & $0.11_{0.09}$ & $-0.83_{0.03}$ & - & $-0.26_{0.09}$ & $-0.73_{0.04}$ & $0.64_{0.05}$ & $0.07_{0.01}$ & -0.80 \\
\hline C18:0 & - & $0.24_{0.09}$ & $0.08_{0.09}$ & $-0.16_{0.08}$ & - & $-0.41_{0.07}$ & $0.41_{0.08}$ & $0.20_{0.09}$ & $-0.28_{0.08}$ & $-0.67_{0.05}$ & $0.09_{0.01}$ \\
\hline
\end{tabular}

${ }^{1} \mathrm{SE}$ in subscript.

${ }^{2}-=$ correlation could not be estimated because of part-whole relationship between the response variables.

${ }^{3}$ Trait: SCFA = small-chain fatty acid; LCFA = long-chain fatty acid; MCFA = medium-chain fatty acid; TFA = trans fatty acid. 
Table 6. Repeatabilities ${ }^{1}$ of 11 fatty acid test-day fractions (\% of total fat) in milk of Danish Holstein (DH) and Danish Jersey (DJ) cattle, based on measurements across lactation (8-305 DIM)

\begin{tabular}{llc}
\hline & \multicolumn{2}{c}{ Repeatability } \\
\cline { 2 - 3 } Trait $^{2}$ & \multicolumn{1}{c}{ DH } & DJ \\
\hline SFA & $0.33_{0.01}$ & $0.24_{0.01}$ \\
MUFA & $0.33_{<0.01}$ & $0.23_{0.01}$ \\
PUFA & $0.16_{<0.01}$ & $0.21_{0.01}$ \\
SCFA & $0.35_{<0.01}$ & $0.31_{0.01}$ \\
MCFA & $0.24_{0.01}$ & $0.22_{0.01}$ \\
LCFA & $0.22_{0.01}$ & $0.21_{0.01}$ \\
TFA & $0.12_{<0.01}$ & $0.12_{0.01}$ \\
C14:0 & $0.14_{0.01}$ & $0.13_{0.01}$ \\
C16:0 & $0.26_{<0.01}$ & $0.27_{0.01}$ \\
C18:0 & $0.18_{0.01}$ & $0.16_{0.01}$ \\
C18:1 & $0.27_{0.01}$ & $0.21_{0.01}$ \\
\hline
\end{tabular}

${ }^{1} \mathrm{SE}$ in subscript.

${ }^{2}$ Trait: SCFA = small-chain fatty acid; LCFA = long-chain fatty acid; MCFA $=$ medium-chain fatty acid; TFA $=$ trans fatty acid .

plain the differences in FA composition for both breeds, especially the difference in C16:0.

\section{Influences of Season and Production Type}

Season had strong effects on the PUFA and C16:0 contents, especially between April and June in organic cows (Figure 1B and 1D). This result was due to the fact that the cows on organic farms were put to pasture and fed fresh grass, which has been shown to influence the FA composition of the cow (Schwendel et al., 2015). Although a proportion of the conventional cows were also put to pasture, we unfortunately did not have access to that information. Thus, the difference between pasture-fed (organic) and barn-fed (conventional) cattle may be even larger than shown here.

Table 7. Genetic $\left(r_{\mathrm{g}}\right)$ and phenotypic $\left(\mathrm{r}_{\mathrm{p}}\right)$ correlations $^{1}$ between 11 fatty acid fractions (\% of total fat) and total fat (g) in milk of Danish Holstein (DH) and Danish Jersey (DJ) across lactation (8-305 DIM)

\begin{tabular}{lrrrrr}
\hline & \multicolumn{3}{c}{$\mathrm{r}_{\mathrm{g}}$} & & \multicolumn{2}{c}{$\mathrm{r}_{\mathrm{p}}$} \\
\cline { 2 - 3 } \cline { 5 - 6 } Trait $^{2}$ & \multicolumn{1}{c}{$\mathrm{DH}$} & \multicolumn{1}{c}{$\mathrm{DJ}$} & & $\mathrm{DH}$ & \multicolumn{1}{c}{$\mathrm{DJ}$} \\
\hline SFA & $0.34_{0.03}$ & $0.26_{0.09}$ & & 0.09 & 0.05 \\
MUFA & $-0.33_{0.03}$ & $-0.26_{0.09}$ & & -0.08 & -0.05 \\
PUFA & $-0.26_{0.04}$ & $-0.11_{0.09}$ & & -0.07 & -0.02 \\
SCFA & $0.33_{0.03}$ & $0.14_{0.09}$ & & 0.15 & 0.14 \\
MCFA & $0.25_{0.04}$ & $0.10_{0.09}$ & & -0.02 & -0.02 \\
LCFA & $-0.19_{0.04}$ & $-0.13_{0.10}$ & & 0.03 & 0.00 \\
TFA & $-0.29_{0.04}$ & $-0.17_{0.10}$ & & -0.07 & -0.04 \\
C14:0 & $0.06_{0.04}$ & $0.07_{0.10}$ & & -0.04 & 0.05 \\
C16:0 & $0.17_{0.04}$ & $0.10_{0.09}$ & & -0.05 & -0.03 \\
C18:0 & $-0.14_{0.04}$ & $0.00_{0.09}$ & & 0.02 & -0.06 \\
C18:1 & $-0.26_{0.04}$ & $-0.26_{0.09}$ & & -0.04 & -0.04 \\
\hline
\end{tabular}

${ }^{1} \mathrm{SE}$ in subscript.

${ }^{2}$ Trait: SCFA = small-chain fatty acid; LCFA = long-chain fatty acid; $\mathrm{MCFA}=$ medium-chain fatty acid; TFA $=$ trans fatty acid.

\section{Heritability}

Most previous studies that estimated heritability for milk FA using MIRS were based on Holstein cattle (Bastin et al., 2011, 2013; Penasa et al., 2015). The number of animals involved in the present study was generally much higher than the number of animals included in previous reports, resulting in much lower standard errors for the estimates. Furthermore, the definition of heritability could differ between studies, which would make direct comparisons difficult. Many estimates are for 305-d lactation yield, whereas our estimates were test day yield heritabilities and, therefore, lower. Bastin et al. (2011, 2013) found much higher heritability estimates for SFA $(0.42 ; 0.49)$ MUFA $(0.21$; $0.26)$, PUFA (0.29; 0.31), and LCFA (0.24; 0.19) compared with our estimates for DH and DJ. Penasa et al. (2015), Petrini et al. (2016), and Narayana et al. (2017) reported higher heritabilities for SFA than we found for DH and DJ. However, some studies reported heritability estimates for PUFA $[0.082$ (Penasa et al., 2015), and 0.11 (Petrini et al., 2016), respectively] that were similar to our results for DH and DJ.

We anticipated that the heritability for UFA would be lower than the heritability for SFA (Bastin et al., 2013; Penasa et al., 2015) because most of the de novosynthesized FA are saturated, due to the low activity of the $\Delta^{9}$ desaturase enzyme on FA shorter than 18 carbons in length (Chilliard et al., 2000). However, in our study, this heritability difference was not found for DJ. For DH, only the PUFA group had a substantially lower heritability compared with the SFA group. One possible reason for our unexpected results is that we estimated heritability from measurements across the lactation period, whereas other studies focused on measurements from a part of the lactation (e.g., Buitenhuis et al., 2014). The effects of genes that influence milk fat composition can change during lactation (Bovenhuis et al., 2015); therefore, heritability could change over lactation. We estimated heritability as an average gene effect across the whole lactation period, which could explain why our heritability estimate was lower than estimates reported in other studies.

\section{Correlation to Total Fat}

Positive effects on human health have been reported from MUFA, PUFA, and SCFA, whereas C16:0 has a negative effect (Bhupathiraju and Tucker, 2011; Flock and Kris-Etherton, 2013; Bier, 2016). The remaining FA groups have overall neutral influences on human health or are part of the previously mentioned FA groups. We do not expect that changing the FA composition would have a major effect on human health, given the 
low expected magnitude of such changes and the small amounts of different FA that humans consume from cow milk. Still, these results suggest a niche market for milk with a healthier FA composition. Genetic correlations between these FA groups and total fat were very different between the DH and DJ populations. These differences could help to explain why DH and DJ cows produced milk with such different fat content and composition profiles.

\section{Possibilities for Implementation}

Recording new phenotypes is always a costly endeavor. Therefore, implementation of monitoring the detailed FA on a routine basis depends on whether farmers can use these new traits in a breeding or management tool. Here, we found that the different FA groups are heritable, suggesting the possibility of selecting for cow milk with a specific FA profile. However, before we can implement this possibility, we must first define a new breeding goal, including the individual FA traits and their weight estimates. We also must estimate the genetic correlations between the individual FA traits and breeding goal traits.

\section{CONCLUSIONS}

The detailed fat compositions of the DH and DJ cows analyzed in this study showed genetic variations. Using MIRS to perform measurements, we found moderate heritabilities for 11 different FA and FA groups. Although the heritabilities between DH and DJ were similar, we found large differences in genetic correlations between total fat and the MUFA, PUFA, SCFA, and C16:0 contents between breeds. In Denmark, interest is increasing for niche products with a more healthy milk fat profile. The genetic variation found in milk FA composition suggests the possibility of changing milk fat composition by genetic selection. An eventual genetic change in the FA profile will, however, be dependent on the inclusion of FA in the breeding goal instead of total amount of fat, and on the economic weights given to the different FA of FA groups.

\section{ACKNOWLEDGMENTS}

The project SOBcows is part of the Organic RDD 2 program, which is coordinated by the International Centre for Research in Organic Food Systems (ICROFS, Tjele, Denmark). This project has received grants from the Green Growth and Development Program (GUDP) under the Danish Ministry of Food, Agriculture, and Fisheries (Copenhagen).

\section{REFERENCES}

Bastin, C., N. Gengler, and H. Soyeurt. 2011. Phenotypic and genetic variability of production traits and milk fatty acid contents across days in milk for Walloon Holstein first-parity cows. J. Dairy Sci. 94:4152-4163.

Bastin, C., H. Soyeurt, and N. Gengler. 2013. Genetic parameters of milk production traits and fatty acid contents in milk for Holstein cows in parity 1-3. J. Anim. Breed. Genet. 130:118-127.

Beaulieu, A. D., and D. L. Palmquist. 1995. Differential effects of high fat diets on fatty acid composition in milk of Jersey and Holstein cows. J. Dairy Sci. 78:1336-1344.

Bhupathiraju, S. N., and K. L. Tucker. 2011. Coronary heart disease prevention: nutrients, foods, and dietary patterns. Clin. Chim. Acta 412:1493-1514.

Bier, D. M. 2016. Saturated fats and cardiovascular disease: Interpretations not as simple as they once were. Crit. Rev. Food Sci. Nutr. $56: 1943-1946$.

Bovenhuis, H., M. H. Visker, H. J. van Valenberg, A. J. Buitenhuis, and J. A. van Arendonk. 2015. Effects of the DGAT1 polymorphism on test-day milk production traits throughout lactation. J. Dairy Sci. 98:6572-6582.

Buitenhuis, B., L. L. Janss, N. A. Poulsen, L. B. Larsen, M. K. Larsen, and P. Sørensen. 2014. Genome-wide association and biological pathway analysis for milk-fat composition in Danish Holstein and Danish Jersey cattle. BMC Genomics 15:1112.

Chilliard, Y., A. Ferlay, Y. Faulconnier, M. Bonnet, J. Rouel, and F. Bocquier. 2000. Adipose tissue metabolism and its role in adaptations to undernutrition in ruminants. Proc. Nutr. Soc. 59:127-134.

Coppa, M., A. Ferlay, C. Chassaing, C. Agabriel, F. Glasser, Y. Chilliard, G. Borreani, R. Barcarolo, T. Baars, D. Kusche, O. M. Harstad, J. Verbič, J. Golecký, and B. Martin. 2013. Prediction of bulk milk fatty acid composition based on farming practices collected through on-farm surveys. J. Dairy Sci. 96:4197-4211.

Craninx, M., A. Steen, H. van Laar, T. van Nespen, J. Martin-Tereso, B. De Baets, and V. Fievez. 2008. Effect of lactation stage on the odd- and branched-chain milk fatty acids of dairy cattle under grazing and indoor conditions. J. Dairy Sci. 91:2662-2677.

De Marchi, M., V. Toffanin, M. Cassandro, and M. Penasa. 2014. Invited review: Mid-infrared spectroscopy as phenotyping tool for milk traits. J. Dairy Sci. 97:1171-1186.

Flock, M. R., and P. M. Kris-Etherton. 2013. Diverse physiological effects of long-chain saturated fatty acids: implications for cardiovascular disease. Curr. Opin. Clin. Nutr. Metab. Care 16:133-140.

Givens, D. I. 2010. Milk and meat in our diet: good or bad for health? Animal 4:1941-1952.

Heck, J. M., H. J. van Valenberg, J. Dijkstra, and A. C. van Hooijdonk. 2009. Seasonal variation in the Dutch raw milk composition. J. Dairy Sci. 92:4745-4755.

Hein, L., L. P. Sørensen, and A. J. Buitenhuis. 2016. Arvbarheder og genetiske sammenhænge - analyser af data fra danske køer. Pages 38-49 in Fedtsyreprofilen i mælk fra malkekøer - potentiale og perspektiver. DCA Rapport nr. 088. Aarhus University, Aarhus, Denmark. http://web.agrsci.dk/djfpublikation/index.asp?action= show\&id $=1227$.

Jensen, R. G., A. M. Ferris, and C. J. Lammi-Keefe. 1991. The composition of milk fat. J. Dairy Sci. 74:3228-3243.

Krag, K., N. A. Poulsen, M. K. Larsen, L. B. Larsen, L. L. Janss, and B. Buitenhuis. 2013. Genetic parameters for milk fatty acids in Danish Holstein cattle based on SNP markers using a Bayesian approach. BMC Genet. 14:79.

Lawrence, G. D. 2013. Dietary fats and health: Dietary recommendations in the context of scientific evidence. Adv. Nutr. 4:294-302.

Madsen, P., and J. Jensen. 2007. An user's guide to DMU. A package for analysing multivariate mixed models. Version 6 , release 4.7 . Accessed Dec. 4, 2017. http://dmu.agrsci.dk/DMU/Doc/Current/ dmuv6_guide.5.2.pdf.

Maurice-van Eijndhoven, M. H., H. Bovenhuis, H. Soyeurt, and M. P. Calus. 2013. Differences in milk fat composition predicted by mid-infrared spectrometry among dairy cattle breeds in the Netherlands. J. Dairy Sci. 96:2570-2582. 
Mensink, R. P., P. L. Zock, A. D. M. Kester, and M.-B. Katan. 2003. Effects of dietary fatty acids and carbohydrates on the ratio of serum total to HDL cholesterol and on serum lipids and apolipoproteins: A meta-analysis of 60 controlled trials. Am. J. Clin. Nutr. 77:1146-1155

Moate, P. J., W. Chalupa, R. C. Boston, and I. J. Lean. 2007. Milk fatty acids. I. Variation in the concentration of individual fatty acids in bovine milk. J. Dairy Sci. 90:4730-4739.

Narayana, S. G., F. S. Schenkel, A. Fleming, A. Koeck, F. Malchiodi, J. Jamrozik, J. Johnston, M. Sargolzaei, and F. Miglior. 2017. Genetic analysis of groups of mid-infrared predicted fatty acids in milk. J. Dairy Sci. 100:4731-4744.

Parodi, P. W. 2016. Dietary guidelines for saturated fatty acids are not supported by the evidence. Int. Dairy J. 52:115-123.

Penasa, M., F. Tiezzi, P. Gottardo, M. Cassandro, and M. De Marchi. 2015. Genetics of milk fatty acid groups predicted during routine data recording in Holstein dairy cattle. Livest. Sci. 173:9-13.

Petrini, J., L. H. Iung, M. A. Rodriguez, M. Salvian, F. Pértille, G. A. Rovadoscki, L. D. Cassoli, L. L. Coutinho, P. F. Machado, G. R. Wiggans, and G. B. Mourão. 2016. Genetic parameters for milk fatty acids, milk yield and quality traits of a Holstein cattle population reared under tropical conditions. J. Anim. Breed. Genet. 133:384-395.
Poulsen, N. A., F. Gustavsson, M. Glantz, M. Paulsson, L. B. Larsen, and M. K. Larsen. 2012. The influence of feed and herd on fatty acid composition in 3 dairy breeds (Danish Holstein, Danish Jersey, and Swedish Red). J. Dairy Sci. 95:6362-6371.

Schwendel, B. H., T. J. Wester, P. C. Morel, M. H. Tavendale, C. Deadman, N. M. Shadbolt, and D. E. Otter. 2015. Invited review: Organic and conventionally produced milk-an evaluation of factors influencing milk composition. J. Dairy Sci. 98:721-746.

Soyeurt, H., P. Dardenne, F. Dehareng, G. Lognay, D. Veselko, M. Marlier, C. Bertozzi, P. Mayeres, and N. Gengler. 2006a. Estimating fatty acid content in cow milk using mid-infrared spectrometry. J. Dairy Sci. 89:3690-3695.

Soyeurt, H., P. Dardenne, A. Gillon, C. Croquet, S. Vanderick, P. Mayeres, C. Bertozzi, and N. Gengler. 2006b. Variation in fatty acid contents of milk and milk fat within and across breeds. J. Dairy Sci. 89:4858-4865.

Stoop, W. M., J. A. van Arendonk, J. M. van Heck, H. J. van Valenberg, and H. Bovenhuis. 2008. Genetic parameters for major fatty acids and milk production traits of Dutch Holstein-Friesians. J. Dairy Sci. 91:385-394

Wilmink, J. B. M. 1987. Adjustment of test-day milk, fat, and protein yield for age, season, and stage of lactation. Livest. Prod. Sci. $16: 335-348$. 